\title{
Nationale en Europese industriepolitiek
}

\author{
Enkele juridische opmerkingen ${ }^{1}$
}

Prof. Mr. R. Barents

\section{Industriepolitiek en Europees recht}

Voor een nationale industriepolitiek is het Europees recht - kort gezegd het EEG-Verdrag en de daarop gebaseerde wetgeving - uiterst relevant. Dit recht begrenst in belangrijke mate de vrijheid van de Lid-Staten om geheel naar eigen inzicht een dergelijke politiek te voeren. Deze beperkingen zijn een rechtstreeks gevolg van de interne markt die momenteel at in belangrijke mate verwezenlijkt is en in een aantal jaren geheel voltooid zal zijn. Verder is dit recht van belang omdat het de instellingen van de EG (Raad en Commissie) bepaalde bevoegdheden toekent die mede voor industriepolitieke doeleinden kunnen worden gebruikt. Deze industriepolitieke betekenis van de EG kan verder toenemen als het Verdrag tot oprichting van de Europese Unie (Verdrag van Maastricht) wordt geratificeerd. Dit verdrag zal, onder meer, tot gevolg hebben dat in het bestaande EEG-Verdrag een nieuw artikel 130 wordt ingevoegd dat bepaalde, specifiek op de industrie betrekking hebbende maatregelen mogelijk maakt.

\section{Wat is industriepolitielk?}

Uiteenzettingen over industriepolitiek kenmerken zich bij uitstek door een uiterst wollig en dubbelzinnig taalgebruik. Om te beginnen wordt vaak gesproken over industriebeleid in plaats van industriepolitiek. 'Beleid', een typisch Nederlandse term², verhult dat het vaak gaat om puur politieke afwegingen die naar plaats, tijd en omstandigheden kunnen verschillen en dat deze afwegingen bepaald niet altijd als economisch of als bedrijfseconomisch rationeel zijn te kwalificeren. De jurist spreekt in dit verband over discretionaire bevoegdheden die het desbetreffende gezag naar eigen politiek inzicht kan aanwenden. Verder wordt het begrip industriepolitiek vaak voorzien van allerlei adjectieven, zoals 'offensief, sturend, voorwaardenscheppend' enzovoort die veelal bedoeld zijn om de desbetreffende maatregelen in politiek opzicht te legitimeren.

Industriepolitiek is, althans voor een jurist, allerminst een eenvormig begrip. Duidelijkheid kan deze zich verschaffen door de desbetreffende als industriepolitiek gepresenteerde maatregelen te analyseren op hun werkingssfeer, doelstellingen en middelen.

De werkingssfeer van een industriepolitiek hangt af van wat men onder industrie verstaat. Gaat het bij industrie om de nijverheid in het algemeen? Zo ja, dan valt daaronder ook de landbouw en de dienstensector. In deze betekenis is industrie eigenlijk een andere uitdrukking voor economische structuur. Een industriepolitiek is dan hoofdzakelijk een globale politiek die vooral gericht is op de beïnvloeding en verbetering van bepaalde generieke structuurcomponenten, zoals kostenpeil, innovatiepotentieel, infrastructuur en kennisniveau van de bevolking. In die optiek richten de maatregelen zich vooral op economische groei

Prof. Mr. R. Barents is verbonden aan het kabinet van de Nederlandse rechter bij het Hof van Justitie van de Europese Gemeenschappen te Luxemburg; hoogleraar Europees gemeenschapsrecht aan de Rijksuniversiteit Limburg. 
als middel tot structuuraanpassing. Het voornaamste coördinatiemiddel is dan het marktmechanisme. In deze benadering kan men bijvoorbeeld het mededingingsrecht zien als een industriepolitiek instrument, gericht op een doelmatige aanpassing aan structuurverandering en het tegengaan van onrendabele economische activiteiten.

Het kan ook gaan om bepaalde sectoren van de economie, zoals de winning van delfstoffen, de produktie van zware kapitaalgoederen, enzovoort. Industriepolitiek is dan in feite identiek met wat een sectorstructuurpolitiek wordt genoemd. Het gaat dan vaak om structuuraanpassing als middel voor economische groei. Coördinatie van de economische beslissingen vindt in sterke mate plaats door de overheid door middel van specifieke interventies.

Met dit onderscheid in werkingssfeer hangt samen het onderscheid naar doelstellingen van een industriepolitiek. Industriepolitiek in de eerstgenoemde betekenis zal voor de Nederlandse situatie dan vooral betrekking hebben op een samenhangend beleid gericht om de Nederlandse economie op optimale wijze te integreren in de grote Europese economie. Men zal dan moeten denken aan onderwijs en onderzoek, infrastructuurwerken (TGV), enzovoort. In de laatstgenoemde betekenis heeft een industriepolitiek vaak een defensief karakter. In de Europese en internationale context betekent dit in vele gevallen dat in feite wordt getracht te ontkomen aan bepaalde structuurveranderingen.

De werkingssfeer en de doelstellingen bepalen tenslotte de middelen van een industriepolitiek. Verhoging van het kennisniveau door bevordering van wetenschappelijk onderzoek is iets anders dan pure ad-hoc reddingssteun afgedwongen door de politiek of door het bedrijfsleven zelf.

Wordt dit analysekader toegepast in de huidige Nederlandse context dan blijkt het bij het begrip industriepolitiek vooral te gaan om maatregelen gericht op bepaalde sectoren van de economie of bepaalde ondernemingen. 'Picking the winners' is de slogan, al kan men zich wel afvragen waarom de 'winners' geholpen moeten worden en niet de 'loosers'. Het instrument bij uitstek is de steunmaatregel, gefinancierd door een deels of geheel door de overheid gecontroleerd fonds dat is of moet worden gevuld met publiek en particulier kapitaal. De toch zeer intrigerende vraag of dit half gerealiseerde beleidsvoornemen wezenlijk iets anders is dan wat vroeger gedaan werd of beoogd werd met de NIB, de NEHEM, de grote projectentoeslag van de WIR, de MIP of de vele vormen van ad-hoc steun (RSV, Volvo, enzovoort) blijft hier buiten beschouwing.

\section{Grenzen aan een nationale industriepolitiek}

Zo opgevat stelt het Europees recht duidelijke grenzen aan een nationale industriepolitiek. Dit kan worden toegelicht aan de hand van een algemene karakterisering van het Europees recht alsmede - in vogelvlucht - op basis van enkele opmerkingen over specifiek industriepolitieke instrumenten.

Meer algemeen gesteld moet men het EEG-Verdrag zien als een soort economische constitutie voor de Lid-Staten en hun burgers die een juridisch kader geeft voor het handelen van de diverse actoren op de markt. Dit heeft in de eerste plaats een inhoudelijk aspect. De interne markt krijgt gestalte door een hele serie van algemene verbodsbepalingen gericht op het verwezenlijken van een vrij verkeer van goederen, personen, diensten en kapitaal. Deze aldus ingestelde markt die heeft geleid tot een vergaande economische interdependentie van de Lid-Staten, wordt aangevuld met een beleid gericht op een effectieve concurrentie door middel van regels voor ondernemingen, staatsondernemingen en steunverlening door de overheid.

Vervolgens is er het institutionele aspect. De EG (Raad en Commissie) is een wetgever die, globaal gesproken, bevoegd is ten aanzien van alles wat direct of indirect te maken heeft met de interne markt. Voor zover de beperkingen voor het instellen en het functioneren van de interne markt niet door de zoeven genoemde algemene verdragsbepalingen zijn verboden, heeft de EG de bevoegdheid om door harmonisatie van nationale wetgevingen de nog bestaande concurrentiebe- 


\section{MAB}

lemmeringen weg te nemen. Nationale maatregelen die met het verdrag of de EG-wetgeving strijdig zijn verliezen hun geldigheid. De burgers van de Lid-Staten kunnen voor hun nationale rechter een rechtstreeks beroep doen op vele bepalingen van het Europees recht, hetgeen praktisch gesproken er toe leidt dat dit strijdige recht of deze strijdige maatregelen niet meer kunnen worden toegepast. Schadevergoeding kan daarvan een van de gevolgen zijn. Verder heeft de Commissie de bevoegdheid om de Lid-Staten wegens schending van hun verdragsverplichtingen voor het $\mathrm{Hof}$ van justitie te brengen.

Deze korte karakterisering van het Europese recht duidt al aan dat het communautaire klimaat voor een nationale industriepolitiek ongunstig is. Een dergelijke politiek zal, wanneer deze van enige betekenis is, leiden tot concurrentiedistorsies op de interne markt. Daardoor is een nationale industriepolitiek zoals opgevat in de hiervoor besproken zin in wezen onverenigbaar met een Europese markt die volgens het verdrag gekenmerkt moet zijn door gelijke concurrentiekansen en een onbelemmerde toegang tot de nationale deelmarkten.

Dit algemene kader heeft belangrijke gevolgen voor diverse instrumenten waardoor een nationale industriepolitiek gestalte kan krijgen.

In de eerste plaats is het niet mogelijk om de invoer of de uitvoer te reguleren door financiële belemmeringen, zoals douanerechten en discriminerende belastingen of door belemmeringen van kwantitatieve aard. Globaal gesproken verbiedt het Europees recht iedere maatregel die de handel tussen Lid-Staten op de een of andere manier kan belemmeren. Het modelleren van nationale wetgeving naar de nationale situatie, een traditionele wijze om de nationale nijverheid te beschermen is daardoor nagenoeg uitgesloten. Een willekeurig voorbeeld om dit te illustreren is het volgende. In Frankrijk waren bedden in het algemeen van kleiner formaat dan in de noordelijke landen. Dit fysiek bepaalde gegeven kwam tot uiting in reeds lang bestaande voorschriften over de omvang van op de Franse markt af te zetten dekens. De invoer en afzet van dekens van groter formaat uit de noordelijke landen werd door dit voorschrift belemmerd aangezien het de buitenlandse fabrikant verplichtte tot aanpassing van zijn produktieproces. Op aandrang van de Commissie werd deze regel afgeschaft. Een ander voorbeeld is het bekende Reinheitsgebot voor bier dat in feite de Duitse markt afsloot voor buitenlandse biersoorten. Aan deze belemmering kwam een einde door een veroordeling van dit land door het Hof van justitie.

In de tweede plaats is het de overheid niet toegestaan om het bedrijfsleven aan te moedigen of te dwingen om kartels te sluiten met bijvoorbeeld als doel de afzet te beperken, minimumprijzen toe te passen, en dergelijke. Dit overheidsoptreden is in de meeste gevallen strijdig met de kartelvoorschriften van het Verdrag in combinatie met de algemene loyaliteitsverplichting van de Lid-Staten om het nuttig effect van het Europees recht niet te frustreren. De lotgevallen van het Nederlandse bouwkartel illustreren deze grenzen aan het overheidsoptreden.

In de derde plaats maken de verdragsregels en de daarop gebaseerde wetgeving over openbare aanbestedingen het gebruik van dit instrument voor nationaal industriepolitieke doeleinden onmogelijk. De Deense overheid ondervond dit onlangs toen het de aanbestedingen voor de bouw van de brug over de Grote belt grotendeels aan Deense ondernemingen toewees. Een kort geding actie van de Commissie voor het Hof van justitie maakte aan deze praktijk een einde.

Het voornaamste industriepolitieke instrument is de steunverlening aan ondernemingen. In vele andere landen heeft dit instrument al een lange geschiedenis achter zich. In Nederland is het tot ontwikkeling gekomen in de tweede helft van de jaren zeventig. Bekende trefwoorden zijn de Wet Investeringsrekening en RSV. Ook aan het gebruik van steunmaatregelen stelt het Verdrag scherpe grenzen. De daarachterliggende filosofie is niet alleen om op deze wijze het kunstmatig verbeteren van concurrentieposities tegen te gaan maar evenzeer om een verspilling van publieke fondsen te voorkomen, in het bijzonder om 'opbieden' tegen te gaan en ondernemingen in staat te stellen de lidstaten tegen elkaar uit te 


\section{MAB}

spelen. De hoofdregel ${ }^{3}$ is dat steunmaatregelen die niet voldoen aan de criteria die het Verdrag ter zake stelt en ten aanzien waarvan de voorgeschreven controleprocedure door de Commissie niet of niet op de juiste wijze is gevolgd, verboden zijn. Het is begrijpelijk dat zowel de Commissie in haar toepassingspraktijk als het Hof van justitie in zijn rechtspraak het begrip steunmaatregel ruim uitlegt. Globaal gesproken is elk voordeel dat een onderneming direct of indirect van overheidswege ontvangt en dat deze niet tegen normale commerciële voorwaarden op de markt kan verkrijgen als een steunmaatregel aan te merken. Bij wijze van voorbeeld een korte opsomming van de voornaamste steunmaatregelen: schenkingen, niet commerciële kapitaaldeelnemingen, laagrentende, gegarandeerde en achtergestelde leningen, afzet- en salarisgaranties, energieleveringen tegen lage prijzen, speciale op de onderneming betrekking hebbende infrastructuurmaatregelen, kwijtscheldingen van belastingen, enzovoort. Vervolgens doet het er niet toe wie de steunmaatregel toepast: de centrale of lagere overheid, functionele overheidsorganen, staatsondernemingen of particuliere lichamen onder formele of materiële controle van de staat.

Elk voornemen om steun toe te passen moet worden gemeld aan de Commissie. Pas als deze toestemming geeft kan de steun ten uitvoer worden gelegd. Niet-aangemelde steunverlening en wel aangemelde maar niet of nog niet goedgekeurde steunverlening is derhalve verboden en onrechtmatig. De sanctie kan een verdragsinbreukprocedure voor het Hof van justitie zijn, een verbod door de nationale rechter om de niet-aangemelde dan wel nog niet goedgekeurde steun toe te passen of een terugvorderingsbevel van de Commissie. Dit korte overzicht toont reeds aan dat niet alleen de overheid bij onrechtmatige steunverlening in grote problemen kan komen maar evenzeer de desbetreffende onderneming. Een terugvorderingsbevel dient steeds ten uitvoer te worden gelegd, zelfs al zou dit leiden tot de ondergang van de betrokken onderneming. Deze summiere opmerkingen over het communautaire steunverleningsregime tonen in ieder geval aan dat het Nederlandse industriefonds te kwalificeren is als een steunverleningsfaciliteit, dat de vorm of de wijze waarop de gelden uit dit fonds worden verstrekt nauwelijks terzake doet en dat elke individuele operatie aangemeld zal moeten worden. De steunontvangende ondernemingen doen er goed aan zich terdege te laten adviseren over de gevolgen van het eventueel niet-naleven van deze regels, de concurrerende en andere belanghebbende dienen zich op de hoogte te stellen van de vaak schromelijk onderschatte rechtsbeschermingsmogelijkheden die het verdrag hen biedt.

In dit verband is het zinvol een moment stil te staan bij het bekende verwijt dat men in Nederlandse kringen wel vaker hoort dat ons land zich in het algemeen aan deze (en andere) regels zou houden terwijl landen als Frankrijk en Italië de communautaire steunverleningsnormen aan hun laars zouden lappen.

Vanuit juridisch oogpunt kan men daarbij de volgende kanttekeningen maken. In de eerste plaats is het maar zeer de vraag of ons land als model kan dienen als het gaat om het zich houden aan regels van Europees recht. De beschikkingspraktijk van de Commissie over steunmaatregelen laat zien dat het Nederlandse blazoen in dit opzicht bepaald niet onbezoedeld is. We zwijgen dan nog maar over de ronduit treurige situatie met betrekking tot de omzetting van richtlijnen in het nationale recht. Verwijt in dit opzicht niet de pot de ketel? In de tweede plaats is de stelling dat vooral de zuidelijke landen meer zouden zondigen in feite een verwijt aan de Commissie die hetzij haar ogen zou sluiten voor met het verdrag strijdige praktijken, hetzij zich in haar beschikkingspraktijk te soepel zou opstellen. In beide gevallen biedt het Verdrag mogelijkheden om dit optreden van de Commissie voor het Hof van justitie aan de kaak te stellen. De rechtspraak biedt voldoende voorbeelden waarin slecht gemotiveerde of inhoudelijke dubieuze beslissingen ten aanzien van steunverlening de rechtmatigheidstoetsing bij de communautaire rechter niet hebben kunnen doorstaan. Dit alles neemt niet weg dat inderdaad de procedure voor de controle van steunmaatregelen niet perfect is en dat inderdaad gevallen bekend zijn waarin de Commissie aan politieke druk is blootgesteld geweest. 


\section{Naar een Europese industriepolitiek?}

Voor een echt nationale industriepolitiek bestaat dus niet veel hoop meer. Een dergelijke politiek biedt in europeesrechtelijk opzicht alleen perspectief als deze een onderdeel vormt van een door de Gemeenschap gecoördineerde industriepolitiek. Deze coördinatie kan plaats vinden op basis van de eerder besproken bepalingen inzake steunverlening. In de loop der tijd heeft de Commissie op de voornaamste terreinen van steunverlening bepaalde richtsnoeren en beleidsbeginselen ontwikkeld in het kader waarvan haar goedkeuringsbevoegdheid met betrekking tot aangemelde steunverleningsoperaties als coördinatie-instrument kan dienen.

Ik refereerde hiervoor reeds aan de omstreden positie van het begrip industriepolitiek op communautair niveau. De Europese verdragen hanteren dit begrip niet maar bevatten wel bevoegdheden die ook voor de industrie van belang kunnen zijn. De EGKS en Euratom-verdragen vormen daarvan een voorbeeld. Diverse bevoegdheden uit het EEG-Verdrag kunnen ook voor industriepolitieke doeleinden worden ingezet, zoals de bevoegdheid tot harmonisatie van wetgeving, de al besproken goedkeuringsbevoegdheid terzake van steunmaatregelen, de controlebevoegdheden met betrekking tot fusies en de handelspolitiek. Om deze gefragmenteerde bevoegdheden in een beter gecoördineerd verband te kunnen uitoefenen is in het Verdrag van Maastricht een artikel opgenomen dat betrekking heeft op de industrie van de Gemeenschap. Dit artikel luidt als volgt:

Titel XIII

INDUSTRIE

Artikel 130

1 De Gemeenschap en de Lid-Staten dragen er zorg voor dat de omstandigheden nodig voor het concurrentievermogen van de industrie van de Gemeenschap aanwezig zijn.

Hiertoe is hun optreden, overeenkomstig een systeem van open en concurrerende markten, erop gericht:
- de aanpassing van de industrie aan structurele wijzigingen te bespoedigen;

- een gunstig klimaat voor het ontplooien van initiatieven en voor de ontwikkeling van ondernemingen in de gehele Gemeenschap, met name het midden- en kleinbedrijf, te bevorderen;

- een gunstig klimaat voor de samenwerking tussen ondernemingen te bevorderen;

- een betere benutting van het industrieel potentieel van het beleid inzake innovatie, onderzoek en technologische ontwikkeling te stimuleren.

2 De Lid-Staten plegen, in verbinding met de Commissie, onderling overleg en coördineren, voor zover nodig, hun activiteiten. De Commissie kan initiatieven nemen om deze coördinatie te bevorderen.

3 De Gemeenschap draagt bij tot de verwezenlijking van de doelstellingen van lid 1 door middel van haar beleid en optreden uit hoofde van andere bepalingen van dit verdrag. De Raad kan op voorstel van de Commissie, na raadpleging van het Europees Parlement en het Economisch en Sociaal Comité, met eenparigheid van stemmen specifieke maatregelen nemen ter ondersteuning van de activiteiten die in de Lid-Staten worden ondernomen om de doelstellingen van lid 1 te verwezenlijken.

Deze titel verschaft geen grondslag voor invoering door de Gemeenschap van maatregelen waardoor de mededinging kan worden vervalst.

De tekst van deze bepaling is niet vrij van wolligheid. De dubbelzinnigheid blijkt reeds uit de aanhef: 'industrie' en niet 'industriepolitiek'. Het laatste begrip druist vooral tegen Duitse en Engelse opvattingen in, laat staan dat ter zake de Gemeenschap een taak zou hebben. De vraag doet zich verder voor wat de juridische betekenis is van de eerste zin. Is dit een resultaatsverplichting - hetgeen een interventionistische politiek impliceert - of een inspanningsverplichting? Uit de vier aandachtsvelden van deze zorgverplichting valt af te leiden dat mogelijke maatregelen met betrekking tot de industrie vooral een globaal en flankerend karakter zouden moeten hebben en dat een industriepolitiek oude stijl, gericht op protectionisme met corporatistische elementen niet bedoeld is. Maar helemaal uitgesloten is dit laatste ook niet. Het is zeer wel voorstelbaar dat een dergelijke politiek gestalte zou kunnen krijgen 


\section{MAB}

voor vooral werkgelegenheidsgevoelige sectoren die zich op communautair niveau in een crisissituatie bevinden. Wellicht zou men kunnen menen dat de laatste zin van deze bepaling zo iets zou uitsluiten. Integendeel echter. Een regel van dezelfde strekking vindt men ook in de titel over de gemeenschappelijke landbouwpolitiek. Als iets in de politiek van de Gemeenschap een interventionistisch en protectionistisch karakter heeft dan is het toch wel de landbouwpolitiek. Daarnaast verwijst artikel 130 uitdrukkelijk naar andere verdragsbepalingen. Artikel 113 over de gemeenschappelijke handelspolitiek sluit protectionistische maatregelen van deze aard zeker niet uit. Kort gezegd wordt deze nieuwe bepaling dus gekenmerkt door een sterke inhoudelijke dubbelzinnigheid. De praktische betekenis van deze bepaling als basis voor industriepolitieke maatregelen wordt echter vooral bepaald door het unanimiteitsvereiste. Gezien de sterke tegenstellingen die op dit punt tussen de Lid-Staten bestaan mag men veronderstellen dat de toepassing van dit artikel een uiterst gecompliceerde aangelegenheid zal zijn.
De conclusie is dat van uit juridisch opzicht aan de ene kant een echt nationale industriepolitiek als een illusie moet worden gekwalificeerd terwijl aan de andere kant kan worden vastgesteld dat op Europees niveau niet meer dan een aanzet daartoe bestaat, afgezien van de vraag wat een dergelijke politiek precies zou moeten of kunnen inhouden. Dit bevestigt dat bij verdergaande integratie, in het bijzonder in een eenmaal verwezenlijkte economische en monetaire unie, beleidsconcurrentie een van de voornaamste issues wordt die het handelen van de nationale overheden zullen bepalen.

\section{Noten}

1 Bewerkte tekst van een inleiding gehouden op 27 januari 1993 tijdens een symposium georganiseerd door het ISEI en de SER.

2 In geen enkele andere taal van de EG kent men het onderscheid tussen beleid en politiek.

3 Een voor niet-juristen goed leesbare verhandeling over de communautaire regels inzake steunverlening is te vinden in het Advies 91/04 van de SER, EG-controle op nationale steun aan ondernemingen. 